\title{
METODOLOGIA DA PROBLEMATIZAÇÃO NO ENSINO EM ENFERMAGEM: UMA REFLEXÃO DO VIVIDO NO PROFAE / RS
}

\author{
Problematization Methodology in Nursing Teaching: \\ A Reflection Lived at the PROFAE / RS \\ Metodología de la Problematización de la Enseñanza en Enfermería: \\ Una Reflexión del Vivido en el PROFAE / RS
}

Diego Schaurich

Fernanda Beheregaray Cabral

Miriam de Abreu Almeida

\begin{abstract}
Resumo
0 artigo configura uma reflexão acerca da experiência de utilização da Metodologia da Problematização no ensino técnico em Enfermagem. Tem como objetivo refletir acerca de algumas possibilidades e dificuldades relacionadas à utilização no ensino técnico em Enfermagem. Para tanto, inicialmente, discorre-se acerca das bases constitutivas da Metodologia da Problematização, passando ao relato da experiência, para então, elencar algumas facilidades e limitações percebidas, quando de sua aplicação na área da saúde e Enfermagem.
\end{abstract}

Palavras-chave: Enfermagem. Ensino. Educação em Enfermagem. Papel do Técnico de Enfermagem.

\begin{abstract}
The article configurates a reflection about the experience of using the Problematization Methodology in Nursing technician teaching. Its objective is to reflect on some possibilities and difficulties about the use in Nursing technician teaching. Therefore, it initially refers to the constitutive basis of the Problematization Methodology passing trough the experience report and then classifying some facilities and limitations perceived when considering its application in the health area and in Nursing.
\end{abstract}

Keywords:

Nursing. Teaching. Education in Nursing. Nurse's Role.

\section{Resumen}

Este artículo configura una reflexión acerca de la experiencia de utilización de la Metodología de la Problematización en la enseñanza de nivel técnico en Enfermería. Tiene como objetivo reflejar acerca de algunas posibilidades y dificultades relacionadas a la utilización en la enseñanza de nivel técnico en Enfermería. Para tanto, inicialmente, se discurre acerca de las bases constitutivas de la Metodología de la Problematización, pasando al relato de experiencia, para después clasificar algunas facilidades y limitaciones percibidas cuando de su aplicación en el área de la salud y Enfermería.

Palabras clave: Enfermería. Enseñanza. Educación en Enfermería. Rol de la Enfermera. 


\section{CONTEXTUALIZANDO A TEMÁTICA}

$\mathrm{Na}$ contemporaneidade, a sociedade tem vivenciado um processo de rápida e constante evolução das ciências e, conseqüentemente, da tecnologia, reflexos de um processo histórico-social que tem culminado na globalização. Nesse sentido, percebe-se que o mundo globalizado vem auxiliando, de forma gradual, na redução das distâncias, na transposição de fronteiras, favorecendo, ainda, a socialização de conhecimentos e tecnologias, integrando diferentes realidades sociais e promovendo o intercâmbio entre diversas culturas.

Sendo assim, conjuntamente com o processo social vislumbrado pelo intensificar da globalização, tem-se o refletir e avaliar diferentes práticas pedagógicas; isto é, o sistema educacional, principalmente neste último século, tem constatado a emergência de diversas perspectivas, distintos modelos teórico-práticos, visando indicar e viabilizar caminhos para que ocorra o processo de ensinar e aprender'. A educação, nessa visão, precisa constituir-se uma práxis educativa integrada à dinâmica cotidiana do indivíduo, possibilitando a ampliação de seus horizontes e a autonomia de pensar suas ações e escolhas, bem como o desenvolvimento da consciência crítico-reflexiva de si, do outro e do seu meio.

Considerando-se que os indivíduos vivenciam diferentes contextos sociais, o processo educativo interativo favorece 0 intercâmbio de saberes e oferece os subsídios necessários para o crescimento de todos os participantes envolvidos e, desse modo, apresenta-se como um importante instrumento de transformação social. Portanto, o fazer pedagógico precisa estar fundamentado em uma abordagem interdisciplinar que possibilite a compreensão de aspectos cognitivos, afetivos, sócio-econômicos, políticos e culturais, constituindo uma prática pedagógica socialmente contextualizada.

Atualmente, os indivíduos vivenciam constantes modificações no nível do saber, da técnica e da ciência, evidenciando a necessidade de superação do atual paradigma bancário educacional ${ }^{2}$ pautado em modelos pedagógicos por vezes estanques, contraditórios e, sobretudo, descontextualizados. E ao pensar a educação como um processo libertador, em que há um fluir de vivências, experiências e conhecimentos - individuais e coletivos - que constituem o ensino-aprendizagem e pela possibilidade de vislumbrar o indivíduo como um ser inacabado e em continuum vir-a-ser, encontram-se subsídios na Metodologia da Problematização ${ }^{3-5}$ como possibilitadora (e facilitadora) do tornar-se mais do indivíduo, considerando que quem ensina aprende, e quem aprende também ensina.

Aliado a estas peculiaridades do sistema educacional, e ao voltar o olhar à área da saúde, percebe-se uma necessidade em substituir o paradigma cartesiano/flexneriano por um modelo holístico ; ou seja, faz-se necessário transcender 0 caráter hospitalocêntrico, medicalizante e fragmentário da assistência, do ensino e dos serviços de saúde, para um modelo que intervenha sobre os determinantes sociais do processo saúde-doença, bem como que vise à promoção da saúde em todos os níveis de atenção e à prevenção de agravos.
Para tanto, acredita-se que um fator importante para a superação deste paradigma esteja na formação do profissional da área da saúde, uma vez que esta precisa, cada vez mais, possibilitar a construção coletiva dos conhecimentos, auxiliar no elo entre a teoria e a prática, suscitar a reflexão e a criticidade $^{7}$, proporcionar ao indivíduo a liberdade para escolher responsavelmente e para criar, em detrimento à transmissão teórica de saberes já instituídos, delimitados e definidos de quem os detém para aqueles que os desconhecem.

E ao vislumbrar este contexto sócio-educacional relacionado à área da saúde, percebe-se que a Metodologia da Problematização emerge como estratégia pedagógica de possível eficácia por propiciar uma ligação e aproximação do ensino com a realidade vivida nos serviços de saúde; além disso, pode oportunizar o habilitar-se tecnicamente não apenas para identificar problemas, mas também para apontar propostas de superação dos mesmos, avançando para além de um olhar curioso, do tipo senso comum, $e$ ganhando status de um ato técnico contextualizado ${ }^{(8: 405)}$.

Este estudo tem por objetivo refletir acerca de algumas possibilidades e dificuldades relacionadas à utilização da Metodologia da Problematização no Ensino Técnico em Enfermagem, apontadas a partir de um relato de experiência. Para tanto, apresentar-se-ão alguns pressupostos que norteiam esta proposta e sua estruturação, tendo por subsídio o Arco de Maguerez; após, será apresentado um relato de experiência acerca da aplicação da Metodologia da Problematização no ensino técnico em enfermagem em campo de estágio. Por fim, serão tecidas algumas reflexões concernentes ao tema em questão, tendo como intuito sinalizar algumas possibilidades e dificuldades emanadas da utilização deste método pedagógico no ensino na área da saúde.

\section{UM OLHAR À METODOLOGIA DA PROBLEMATIZAÇÃO}

Atualmente, muitas são as tendências e metodologias educacionais estudadas, pesquisadas, experimentadas e aplicadas ao ensino no país, não muito diferente do que tem ocorrido em âmbito internacional. Contudo percebe-se que tem havido um avanço nas tecnologias educativas, principalmente se for considerado que, simultaneamente, alternativas mais tradicionais de educação têm sido questionadas e outras têm surgido, as quais possibilitam e demonstram maior atenção e interesse pelo dinamismo existente nos campos e nas ciências social, política, educacional, religiosa, entre outras.

Assim, pode-se exemplificar o exposto pelo repensar e refletir acerca da utilização da pedagogia da transmissão que, em uma perspectiva centrada na educação bancária ${ }^{2,9}$, isto é, em uma educação que se fundamenta na transferência de conhecimentos e saberes de quem os detém (o professor) para indivíduos ainda pouco desenvolvidos em relação a tal temática ou assunto (os alunos), tem sido usada indiscriminadamente ao longo do processo histórico educacional nos cenários de ensino. Em virtude deste ressignificar de conceitos e valores, na atualidade, um outro método pedagógico tem despontado como mais interessante ao 
desenvolvimento intelectual, profissional e coletivo: a Metodologia da Problematização.

A Metodologia da Problematização foi proposta, inicialmente, por Bordenave e Pereira ${ }^{10}$ e revela-se como estratégia inovadora na área educacional, seja como método de estudo ou de ensino, tendo como fundamento o pensamento freireano. Esses autores utilizaram-se de um esquema elaborado por Charles Maguerez denominado Método do Arco e que veio ao encontro deste modelo de ensino- aprendizagem por considerar como premissa da educação, a realidade circundante ao indivíduo, suas vivências e experiências, seus saberes e conhecimentos apriorísticos; por objetivar o desenvolvimento cognitivo, crítico, reflexivo e autônomo dos educandos e do educador.

E é por este viés que se deve compreender a Metodologia da Problematização, ou seja, como um processo que privilegia a troca de conhecimentos, de saberes e de experiências entre os educandos e o educador, considerando que ambos apresentam uma história individual - e coletiva - e um contexto social compartilhado. Esta forma de perceber e desenvolver este método pedagógico vislumbra o educando e o educador como detentores de um saber apriorístico que, no momento em que entram em relação dialógica e educativa, direcionam seus conhecimentos para uma convergência: a mudança individual e coletiva e, conseqüentemente, a transformação da realidade de maneira crítica e criativa.

Assim sendo, nesse ponto do texto, torna-se oportuno apresentar o Método do Arco. Contudo, faz-se relevante destacar que esse caminho metodológico tem como pressuposto as situações vivenciadas e experimentadas pelos indivíduos e consideradas problemáticas. A estrutura do Arco utilizada pela Metodologia da Problematização tem seu ponto de partida na realidade, seguindo uma trajetória de observações e focalizações do problema, reflexões, teorizações, hipóteses de solução e proposições para, desta maneira, chegar novamente à realidade e poder transcendê-la, transformá-la, alterá-la.

A primeira etapa do Arco denomina-se Observação da Realidade e caracteriza-se por ser o momento em que se torna oportuno aos educandos e ao educador lançar um olhar atento e crítico ao vivido, percebê-lo de forma diferenciada e identificar aquilo que está se mostrando como preocupante, inconsistente ${ }^{10}$, isto é, o problema a ser estudado e desvelado pelo processo ensino-aprendizagem. Essa observação torna oportuno refletir criticamente acerca das coisas que estão postas como verdades e que necessitam ser melhoradas, aperfeiçoadas, além de possibilitar um olhar mais atento fazendo com que emirjam aspectos importantes da realidade social.

Com o prosseguir da observação cuidadosa da problemática pelos educandos e educador, surge a necessidade de elencar Pontos-Chave no intuito de priorizá-los e caracterizá-los de forma mais consistente. De acordo com Berbel 10:04, esta fase tem por característica ser um momento de síntese após a observação inicial; é o momento da definição do que vai ser estudado sobre o problema; é o momento de definir os aspectos que precisam ser conhecidos e melhor compreendidos a fim de se buscar uma resposta para esse problema. Esta etapa precisa ser de grande flexibilidade, pois propicia o diálogo entre educandos e educador, visando definir quais serão os pontos-chave relevantes para a compreensão de determinada problemática, pois são eles os orientadores da continuidade do processo metodológico.

Na seqüência, tem-se a Teorização que compreende o estudo propriamente dito acerca dos pontos-chave, sendo o momento da investigação, da pesquisa, da análise do que existe em relação a tal assunto ou tema - o problema. Esta fase possibilitará aos educandos e educador um ampliar de horizontes teóricos, um aprofundar de conhecimentos acerca do problema estudado, com o objetivo de possibilitar uma comparação com as percepções iniciais, uma revisão dos pontoschave, um fortalecimento do que se conhecia anteriormente em uma visão mais do senso comum, passando, agora, para uma perspectiva mais científica. Consoante 0 apresentado por Berbel ${ }^{4: 18}$, esta etapa representa uma oportunidade de aprendizagem efetiva, no contato e no confronto o mais direto possivel com a realidade, onde a ação humana ou os fenômenos da natureza ocorrem concretamente.

Após a teorização de aspectos importantes referentes à problemática, segue-se o momento de definir e construir Hipóteses de Solução, que tem como premissa a criatividade inerente ao indivíduo como ser inconcluso. Este olhar-agir criativo e reflexivo propicia aos educandos e educador uma percepção do problema, de sua gênese, de seu entorno e repercussões individuais e coletivas; precisa estar presente para possibilitar um outro pensar e agir, uma superação dos conhecimentos, ações e atitudes já existentes e construir novos saberes e ações a fim de viabilizar mudanças sociais. Berbel ${ }^{10: 06}$ compreende que é preciso ter ações novas, ações diferentes, elaboradas de uma outra maneira para se poder exercer uma diferença na realidade de onde se extraiu o problema.

Para finalizar as etapas do Método do Arco, após um movimento que tem o mesmo ponto de partida e de chegada, faz-se necessário que ocorra a Aplicação à Realidade; esta etapa prevê que, após a reflexão da realidade, do repensar acerca de pontos problemáticos, de pesquisar, teorizar e apropriar-se de hipóteses resolutivas, se volte à realidade, visando transformá-la, alterá-la. É um momento de ação, de prática, de agir sobre aquela realidade vislumbrada - de forma individual e coletiva - como problemática. É importante salientar que nem sempre são possíveis grandes transformações, mas toda e qualquer mudança de pensamento, de forma de perceber, no modo de pensar, na maneira de lançar criticamente olhares inovadores ao que está posto, deve ser considerada positiva e como possível solução ao problema ${ }^{10}$.

Nesse sentido, realizando aproximações com o foco da temática proposto para este artigo, ou seja, a de refletir acerca da utilização da Metodologia da Problematização na prática do ensino técnico em Enfermagem, acredita-se que esta proposta vem ao encontro do ideário de possibilidade de mudança da realidade, tão necessária à área da saúde. Esta metodologia, como estratégia de educação, tem o intuito de preparar 0 estudante / ser humano para tomar consciência do seu mundo e atuar também intencionalmente para transformá-lo, sempre para melhor, para um mundo e uma sociedade que permitam uma vida mais digna para o próprio homem ${ }^{10: 10}$. 


\section{A PROBLEMATIZAÇÃO NO ENSINO EM ENFERMAGEM: RELATO DE EXPERIÊNCIA}

Para este momento pretende-se tecer considerações sobre cenas da prática experimentada ao utilizar a Metodologia da Problematização no ensino técnico em Enfermagem, mais especificamente ao descrever como ocorre um dia de aula prática, ao ter por subsídio este processo pedagógico e os pressupostos de Freire ${ }^{2} .0$ cenário em que se deu a possibilidade de utilização da referida metodologia foi o da Complementação da Qualificação Profissional (CQP), uma das vertentes do Projeto de Profissionalização dos Trabalhadores da Área de Enfermagem (PROFAE), desenvolvido por uma Instituição Federal no interior do Estado do Rio Grande do Sul (RS).

O PROFAE é um projeto do Ministério da Saúde e tem como premissa os Referenciais Curriculares Nacionais da Educação Profissional da Área de Nível Técnico ${ }^{11}$. Portanto, ele vem buscando implementar o currículo integrado direcionado para a formação de competências e habilidades. Este desafio reveste-se de características peculiares como a extensa área geográfica do projeto no Estado; as especificidades de cada municíio; a diversidade da clientela; a descentralização das atividades de ensinoaprendizagem; e a própria escolha de uma metodologia com base na problematização da realidade do educando trabalhador.

0 Projeto Político Pedagógico em que se desenvolveu a experiência que será relatada tem como estrutura de curso uma carga horária de 230 teóricas e 460 prático-teóricas ${ }^{12}$. Faz-se relevante destacar que os eventos aqui apresentados são reflexo de uma vivência experimentada em diversos municípios - de pequeno e médio portes - do interior do Estado, uma vez que a proposta educacional é a mesma; é importante ressaltar ainda, que as possibilidades e dificuldades também foram percebidas em vários cenários educacionais em que a proposta se desenvolveu. Pretende-se então, proceder a uma descrição reflexiva da experiência de ensino-aprendizagem vivenciada em um dia de aula prática no ensino técnico em Enfermagem, em que foi utilizado o Método do Arco da Metodologia da Problematização.

Considera-se que tanto os educandos quanto o educador, ao chegarem ao campo de práticas hospitalares, têm o primeiro contato com a realidade, uma vez que, embora já estejam desenvolvendo o processo de cuidado há algum tempo nesses locais, as mudanças e transformações da área da saúde ocorrem com muita freqüência e de modo rápido. Desta forma, são possibilitados ao grupo uma visita inicial às enfermarias e um breve diálogo com os pacientes e seus acompanhantes, a fim de melhor se familiarizarem com o cenário. Essa etapa caracteriza-se por ser a aplicação do primeiro momento da Metodologia do Arco: a observação da realidade.

Essa observação, ainda que incipiente, prossegue quando, então, os educandos assumem e desenvolvem os cuidados de Enfermagem para determinados pacientes e, assim conseguem conhecer um pouco mais sobre a pessoa a ser cuidada e acerca do contexto desse ser, incluindo, também, os aspectos físicos. Nesse sentido, com a focalização dos problemas que precisam ser resolvidos, os educandos conjuntamente com o educador, passam a elencar as necessidades de cuidado de cada paciente, fase esta compreendida como o levantamento dos pontoschave, os quais subsidiarão a continuidade do processo ensinoaprendizagem, no contexto prático.

Os pontos-chave representados pelos cuidados que necessitam ser atendidos no paciente, como por exemplo, a realização de um curativo, a alternância de decúbito, a administração de medicamentos, são, então, teorizados, ou seja, o educando e o educador revisam os aspectos considerados importantes para a execução da técnica tais como os materiais necessários para se fazer um curativo, o auxílio nos cálculos para a preparação dos medicamentos, entre outros, sendo ressaltados, também, os aspectos inerentes ao diálogo, à interação entre quem cuida e quem é cuidado, o respeito e os preceitos éticos.

Após a rápida teorização da problemática identificada pelos educandos, segue-se o momento em que este passa a construir as hipóteses de solução dos problemas, isto é, a proposição de um plano de cuidados em Enfermagem com vistas à ampliação dos conhecimentos e ações já existentes, favorecendo a construção de novos saberes e de diferentes possibilidades para a realização da prática. Nessa fase, o educando pensa, reflete e elabora uma outra forma de desenvolver o procedimento, a maneira de buscar a interação com o paciente, descobrindo uma forma de, mesmo durante a realização da técnica, procurar envolver o acompanhante do paciente, no processo de cuidar.

Para finalizar a narrativa de utilização do Método do Arco de Maguerez, segue-se a aplicação à realidade quando o educando implementa, junto ao paciente, o plano de cuidados em Enfermagem que, anteriormente, havia elaborado, tendo por intuito maior provocar alguma modificação que culmine na melhoria do contexto de cuidado vivido pelo paciente e pelo seu acompanhante, e até mesmo na estruturação da prática na própria instituição em que está inserido. Este momento de ação-reflexiva possibilita aos educandos e ao educador lançarem um outro e diferente olhar à realidade, mais crítico e criativo.

Faz-se importante salientar que não são necessárias transformações extremas e radicais na estrutura institucional, mas que o fato de o educando ter repensado e refletido acerca de seu ser, saber efazer e, ainda, acerca da pessoa de quem cuida, já se configura como uma importante etapa de crescimento e aprendizado.

\section{REFLEXÕES DO VIVIDO: CONSIDERANDO FACILIDADES E DIFICULDADES}

Após essas considerações sobre cenas práticas que abrangeram a aplicação da Metodologia da Problematização no ensino prático em Enfermagem, tentar-se-á, por meio de um movimento de reflexão da práxis, elencar algumas possibilidades e dificuldades percebidas na utilização desta proposta pedagógica na Enfermagem. Considera-se esta metodologia uma possibilidade para se provocar as transformações necessárias no que diz respeito à saúde suas políticas, recursos humanos e financeiros, métodos e objetivos - tanto quanto na prática da Enfermagem.

Parte-se da compreensão de que a problematização é um conceito operacional através do qual o conhecimento vai sendo 
apropriado a partir da análise de conteúdos e situações concretas, propiciando aproximações sucessivas do objeto em discussão, até a formulação, sistematização e/ou 0 esclarecimento de conceitos ${ }^{8: 405}$. Destaca-se, ainda, a preocupação premente dessa proposta pedagógica em auxiliar na formação de estudantes e enfermeiros críticos, reflexivos e criativos em relação aos problemas vividos de forma individual e coletiva; espera-se que estejam realmente habilitados, não apenas para a transmissão dos conteúdos técnico-científicos, mas para estimular e apoiar o desenvolvimento de novos profissionais e cidadãos, conscientes e atuantes em seu meio ${ }^{4: 23}$.

Para tanto, serão, inicialmente, tecidas reflexões acerca de alguns aspectos considerados específicos e fundamentais para o setor saúde e que podem ser alcançados por meio da utilização da Metodologia da Problematização. Faz-se também importante salientar que os referidos aspectos, longe de se encontrarem estáticos e formalmente delimitados, estão em contínua dinamicidade, transcendendo suas próprias limitações e influenciando e sendo influenciados uns pelos outros, formando um teia de relações.

0 primeiro aspecto em que este método poderá auxiliar a área da saúde refere-se à transcendência do modelo biomédico dominante para um modelo holístico, ou seja, por possibilitar a crítica e a reflexão, esta proposta metodológica pode ajudar a transpor o modelo curativista e medicalizante, que percebe 0 ser humano de forma fragmentada e se utiliza de um conhecimento altamente especializado, para um outro paradigma que estimula o desenvolvimento da cidadania, possibilitando a compreensão do ser humano socialmente inserido, vislumbrandoo de forma holística e humanizada, além de priorizar a prevenção de agravos e a promoção à saúde.

Isto poderá ser alcançado por meio de sucessivas percepções e reflexões acerca da realidade, definindo os pontos-chave principais, os quais serão subsídios norteadores da teoria que favorece ao estudante um conhecimento mais amplo e aprofundado em diferentes âmbitos da prática cotidiana, bem como o emergir de hipóteses de solução para, então, iniciar a transformação. Contudo, compreende-se que este é um processo lento e gradual, que depende do envolvimento, empenho e dedicação de todos - estudantes e profissionais da área da saúde, gestores, docentes, usuários do sistema, governos, entre outros - a fim de que ocorra esta mudança paradigmática.

Deve ser ressaltado que outra questão preocupante, mais específica do processo de ensinar-aprender, é a separação, a dicotomia existente entre a teoria e a prática. Entende-se, entretanto, que a Metodologia da Problematização poderá auxiliar na superação desse status quo propiciando que 0 conhecimento adquirido, aprofundado, ampliado e construído tenha sua gênese assertiva na prática, no vivido pelo indivíduo e no percebido por este como problema. Assim, a fragmentação teoria-prática poderá ser minimizada uma vez que uma estaria condicionada à outra, isto é, a fim de que a teorização aconteça, será necessário um olhar atento, um experienciar da realidade do processo ensino-aprendizagem, a fim de que a teoria tenha como finalidade apontar soluções possíveis para retornar à prática e poder transformá-la, em algum nível.
No que tange às ações da Enfermagem, compreende-se que a Metodologia da Problematização poderá auxiliar em que a educação em saúde se torne também um processo que desenvolva no usuário do serviço de saúde o sentido e a importância do exercício da cidadania e de sua participação como sujeito desse processo. Atualmente, percebe-se que, por meio das relações de poder estabelecidas entre o profissional e o paciente, existe uma submissão deste último, pois os referidos profissionais the impõem suas crenças e valores, suas concepções de certo e errado, visando mudar ou corrigir ações e atitudes do paciente, na grande maioria das vezes descontextualizadas da realidade por este experienciada ${ }^{13}$.

Nesse sentido, acredita-se que a problematização poderá propiciar uma aproximação entre o discurso popular e o da ciência - Enfermagem -, à medida que a educação em saúde, as orientações e informações partirem do contexto vivido pelo usuário, sendo repensada, refletida e teorizada pelo binômio profissional-paciente, com o intuito de obter hipóteses de solução que retornem a esta realidade e a altere, possibilitando ao paciente a oportunidade de fazer escolhas conscientes, livres e responsáveis. Assim, entende-se estar propiciando o despertar de indivíduos críticos, cidadãos, reflexivos, autônomos e criativos.

Ainda, percebe-se a importância da problematização como estratégia pedagógica para o educar/cuidar em Enfermagem, pois contribui para a formação de educandos mais críticos e reflexivos, que possam construir o conhecimento em parceria com os educadores, tendo como finalidade um olhar inovador e transformador das situações de saúde-doença e seus respectivos cuidados que fazem parte da realidade vivida. Segundo Godoy ${ }^{14: 599}$, esta proposta

Fundamenta-se na certeza de que o aluno é sujeito ativo no processo de construção do seu conhecimento, cumprindo ao professor a condução dos processos de ensino e aprendizagem pelo permanente desafio do raciocínio do aluno e pela progressiva integração de novos conhecimentos às experiências prévias.

Compreende-se, então, que esta metodologia poderá auxiliar na superação do modelo tradicional de ensino para uma outra forma de educar, em que as percepç̃es partam da prática vivida, elencandose pontos-chave que norteiem a teorização e a pesquisa para suscitar inúmeras soluções possíveis, visando à formação de ações que propiciem uma alteração melhorada da realidade. Entende-se que talvez este seja o ponto primordial (a formação na saúde), o cerne da transformação, imprescindível para que se minimizem pontos críticos tais como as relações de poder e submissão, muitas vezes presentes na educação em saúde, a dicotomia existente entre 0 ensino e a prática, a teoria e a assistência, a academia e o mundo do trabalho, bem como a superação da visão biologicista para uma visão mais holística como paradigma da área da saúde.

Há também que se reconhecer algumas dificuldades encontradas ao se utilizar a Metodologia da Problematização, a partir das vivências e experiências no ensino em Enfermagem, quais sejam: esta proposta metodológica pode ser aplicada a assuntos e a conteúdos específicos, não podendo ser utilizada de forma indiscriminada, mas sim, em associação a outras propostas pedagógicas ${ }^{5}$. A problematização, por não apresentar 
um roteiro delimitado de saberes a serem refletidos e construídos, precisa envolver a interdisciplinaridade de conhecimentos - caminho ainda incipiente para muitos educandos e educadores, o que poderá representar um empecilho a sua escolha e utilização. Esta metodologia exige uma interligação com as demais metodologias e conteúdos e um espaço temporal que, muitas vezes, pode não estar disponível nas grades curriculares e/ou nas relações de ensinoaprendizagem, principalmente quando considerados os espaços de prática. A problematização revela-se como uma proposta nova e inovadora que precisa ser mais bem apreendida e pesquisada, por meio de constantes aproximações com a prática, a fim de que a teoria que a envolve seja mais bem compreendida e que hipóteses de solução de problemas e lacunas se façam presentes para que, ao retornar à realidade, a transformação e a mudança aconteçam e o conhecimento seja constituído, avaliado e reavaliado.

Percebe-se ainda que a prática pedagógica da problematização, quando aplicada à formação de profissionais na área da saúde (Enfermagem) precisa também respeitar a individualidade do ser humano, suas concepções únicas, contemplar as dimensões biológicas, psicológicas, históricas, culturais, filosóficas e sociais do processo saúde-doença, possibilitando, desta maneira, maior aproximação entre a teoria e a prática, entre as ações curativas e preventivas, entre a educação e o mercado de trabalho, tanto em uma perspectiva individual quanto coletiva.

\section{CONSIDERAÇÕES FINAIS}

0 mundo globalizado da atualidade, associado a suas repercussões e conseqüências, tem exigido cada vez mais dos indivíduos novas posturas em face dos obstáculos e desafios impostos. Surge, assim, a necessidade de formação de indivíduos autônomos, livres, críticos, reflexivos, inovadores e criativos. Nesse sentido, e seguindo essa tendência de mudanças, a área da educação tem repensado os seus métodos pedagógicos, visando avaliar e reavaliar o então em voga sistema bancário e de transmissão de saberes, para desenvolver e aprimorar modelos mais flexíveis e contextuais, em que os

\section{Referências}

1. Bordenave JD, Pereira AM. Estratégias de ensino-aprendizagem. $24^{\mathrm{a}}$ ed. Petrópolis (RJ): Vozes; 2002.

2. Freire P. Pedagogia da autonomia: saberes necessários à prática educativa. 23a ed. São Paulo (SP): Paz e Terra; 1996.

3. Berbel NAN. Metodologia da problematização: experiências com questões de ensino superior. Londrina (PR): Ed. UEL; 1998 a.

4. Berbel NAN. Metodologia da problematização. Experiências com questões de ensino superior, ensino médio e clínica. Londrina (PR): Ed. UEL; 1998 b.

5. Berbel NAN. Metodologia da problematização: fundamentos e aplicações. Londrina (PR): Ed. UEL; 1999a.

6. Capra F. 0 ponto de mutação. São Paulo (SP): Cultrix; 1980. conhecimentos sejam construídos conjuntamente a partir das vivências e experiências dos educandos e educadores.

As diretrizes pedagógicas que norteiam as ações dessa nova prática do ensino poderão estar centradas na Metodologia da Problematização, a qual considera a aprendizagem a partir da realidade dos educandos com a finalidade de apreendê-la e compreendê-la, apoiar o processo de construção do conhecimento e transformá-la ${ }^{15}$. Sendo assim, a realidade do educando é percebida não como um fim em si mesma, mas como subsídio para o encaminhamento de novas propostas ante os problemas apresentados, possibilitando interação entre ensino, teoria e prática, buscando soluções específicas e originais para diferentes situações, integrando educação, trabalho e comunidade, sob uma perspectiva crítico-reflexiva.

Faz-se essencial compreender a necessidade em superar 0 modelo tradicional de ensino, a quantidade excessiva de conteúdos e técnicas repassados, o distanciamento existente entre a academia e o mercado de trabalho, bem como a dicotomia entre a teoria e a prática, o ensino e a assistência, entre outras questões. A Metodologia da Problematização quando aplicada à Enfermagem acaba por expor, também, a fragilidade do modelo biologicista operante na área da saúde, a separação entre a prática e o ensino, o exercício de poder permeado na relação entre o profissional e o paciente e a formação acrítica e pouco reflexiva a que está subordinado o indivíduo (educando), entre outros aspectos não menos importantes.

Cabe registrar que neste artigo não se teve o intuito de finalizar ou esgotar essa discussão, nem o de limitar as inúmeras possibilidades de superação vislumbradas por esta proposta pedagógica ou restringir os diversos outros olhares possíveis de serem lançados à utilização desta metodologia no ensino em Enfermagem.

Concluindo, é preciso salientar que os aspectos aqui expostos são resultantes de algumas reflexões emanadas da prática e que revelam as potencialidades e limitações, as facilidades e as dificuldades deste método como tecnologia educacional. Para além disso, acredita-se que a Metodologia da Problematização poderá auxiliar na superação dos problemas ainda existentes nas áreas da saúde e educação, assim como no educar e cuidar em Enfermagem.

7. Guimarães GL. 0 perfil do enfermeiro-educador para o ensino de graduação. Esc. Anna Nery Rev Enferm 2005; 9(2): 255-60.

8. Santos Filho SB. Métodos de ensino-aprendizagem na prática docente em enfermagem: abordagens problematizadoras em disciplinas de Saúde Coletiva. REME :Rev Min Enferm 2004; 8(3): 402-8.

9. Bordenave JD. Alguns fatores pedagógicos. Notas preliminares. In: Capacitação Pedagógica para Instrutor/Supervisor Área da Saúde. Texto traduzido e adaptado do artigo: la transferencia de tecnologia apropriada ao pequeno agricultor. Rev Interamericana Educação de Adultos 1983; 3(1-2): 19-26.

10. Berbel NAN. A metodologia da problematização e os ensinamentos de Paulo Freire: uma relação mais que perfeita. In: Berbel NAN. Metodologia da problematização: fundamentos e aplicações. Londrina (PR): Ed. UEL; 1999 b. p. 1-28. 
11. Ministério da Educação e Cultura (BR). Referenciais curriculares nacionais da educação profissional de nível técnico. Brasilia (DF): PROEP; 2000.

12. Padoin SMM, Bohrer INT, organizadoras. Enfermagem. Caderno didático 1: as diretrizes. Santa Maria (RS): Ed. UFSM; 2002.

13. Oliveira DL. A 'nova' saúde pública e a promoção da saúde via educação: entre a tradição e a inovação. Rev Latino-am Enfermagem 2005; 13(3): 423-31.

14. Godoy CB. 0 curso de enfermagem da Universidade Estadual de Londrina na construção de uma nova proposta pedagógica. Rev Latino-am Enferm 2002; 10(4): 596-03.

15. Schaurich D, Paula CC, Fontoura VAF, Padoin SMM. Discutindo AIDS na escola por meio da pedagogia da problematização. In: $1^{\circ}$ Seminário Brasileiro de Estudos Culturais em Educação: poder, identidade e diferença. [CD ROM]. Canoas (RS): Ed. ULBRA; 2004. 13 p.

\section{Nota}

a Trabalho apresentado na disciplina de Abordagens do Ensino de Enfermagem do Programa de Pós-Graduação da Escola de Enfermagem da Universidade Federal do Rio Grande do Sul (UFRGS).

\section{Sobre os Autores}

\section{Diego Schaurich}

Enfermeiro. Mestrando do Programa de Pós-Graduação da Escola de Enfermagem da UFRGS; Membro do Grupo de Estudos do Cuidado em Enfermagem à Saúde nas Etapas da Vida (CEVIDA - UFRGS); Membro do Grupo de Estudo e Pesquisa em Enfermagem e Saúde (GEPES) da Universidade Federal de Santa Maria (UFSM/RS). Bolsista CNPq.

\section{Fernanda Beheregaray Cabral}

Enfermeira. Mestranda do Programa de Pós-Graduação da Escola de Enfermagem da UFRGS; Coordenadora Pedagógica do Projeto PROFAE; Docente do Curso de Graduação em Enfermagem da Universidade Regional Integrada - URI Santiago/RS.

\section{Miriam de Abreu Almeida}

Enfermeira. Professora Adjunta do Departamento de Enfermagem Médico-Cirúrgica da Escola de Enfermagem da UFRGS. Doutora em Educação pela Pontifícia Universidade Católica do Rio Grande do Sul (PUCRS). 